This item was submitted to Loughborough's Research Repository by the author.

Items in Figshare are protected by copyright, with all rights reserved, unless otherwise indicated.

\title{
RLC effects in fine pitch anisotropic conductive film connections
}

PLEASE CITE THE PUBLISHED VERSION

PUBLISHER

(C) Emerald

VERSION

AM (Accepted Manuscript)

LICENCE

CC BY-NC-ND 4.0

REPOSITORY RECORD

Dou, Guangbin, Y.C. Chan, J.E. Morris, and David C. Whalley. 2019. "RLC Effects in Fine Pitch Anisotropic Conductive Film Connections”. figshare. https://hdl.handle.net/2134/5277. 
This item was submitted to Loughborough's Institutional Repository (https://dspace.lboro.ac.uk/) by the author and is made available under the following Creative Commons Licence conditions.

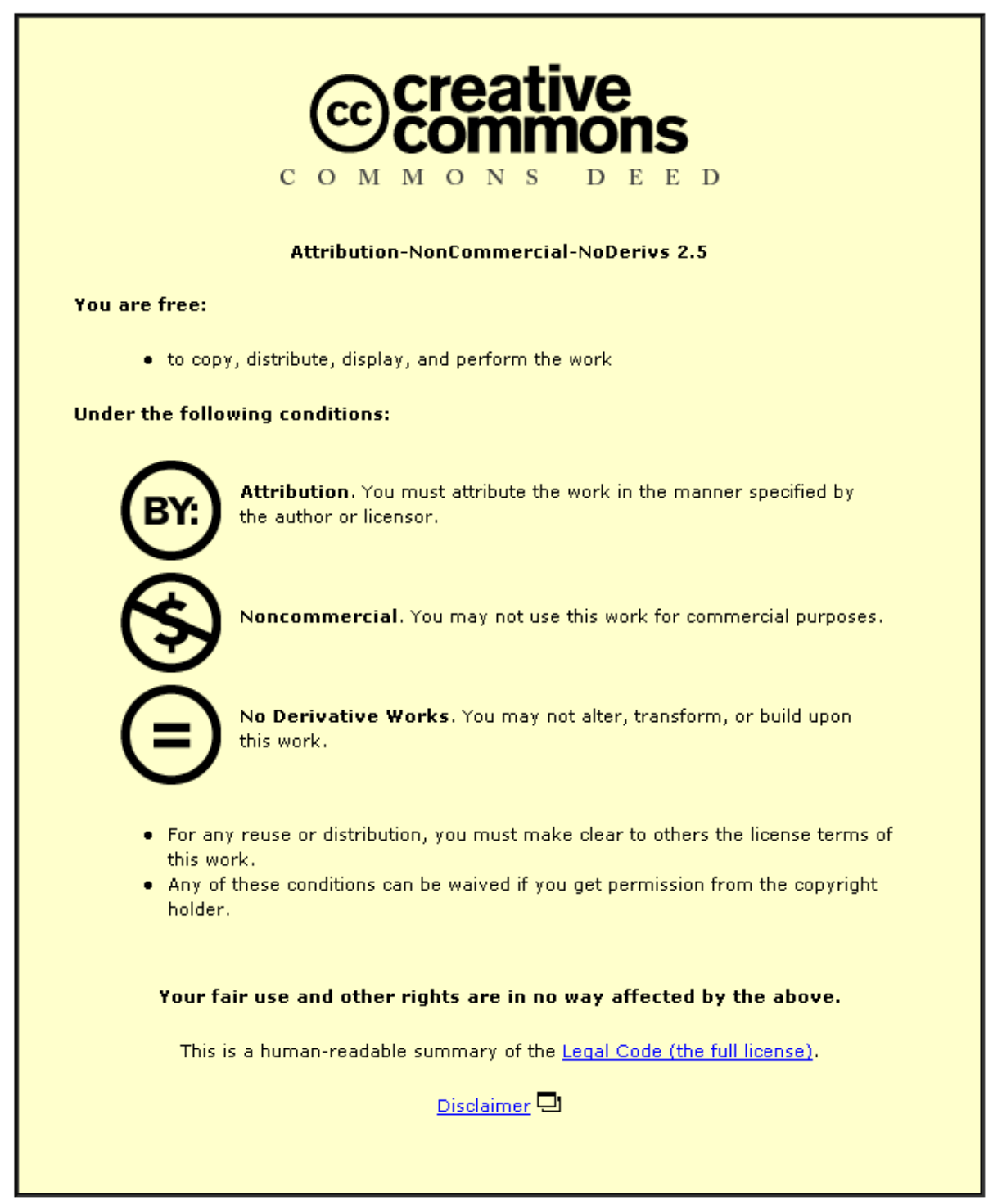

For the full text of this licence, please go to: http://creativecommons.org/licenses/by-nc-nd/2.5/ 


\title{
RLC EFFECTS IN FINE PITCH ANISOTROPIC CONDUCTIVE FILM CONNECTIONS
}

\author{
G. Dou**, Y. C. Chan*, J. E. Morris ${ }^{\#}$ and D. C. Whalley** \\ **Wolfson School of Mechanical and Manufacturing Engineering, Loughborough \\ University, Leics, UK, LE11 3TU \\ *Department of Electronic Engineering, City University of Hong Kong, 83 Tat Chee \\ Avenue, Kowloon, Hong Kong \\ \#Electrical and Computer Engineering, Portland State University, USA
}

Email: eeycchan@cityu.edu.hk, gb.dou@lboro.ac.uk 


\section{Research paper}

\section{Purpose}

The resistance, capacitance and inductance of Anisotropic Conductive Film (ACF) connections determine their high frequency electrical characteristics. The presence of capacitance and inductance in the ACF joint contributes to time delays and crosstalk noise as well as simultaneous switching noise (SSN) within the circuit. The purpose of this paper is to establish an experimental method for estimating the capacitance and inductance of a typical ACF connection. This can help to provide a more detailed understanding of the high frequency performance of ACF assemblies.

\section{Design/methodology/approach}

Experiments on the transient response of an ACF joint were performed using a digital oscilloscope capable of achieving the required $n s$ resolution. An equivalent circuit model is proposed in order to quantify the capacitance $(C)$ and inductance $(L)$ of a typical ACF connection and this model is fitted to the experimental data. The equivalent model consisted of two resistors, an inductor, and a capacitor.

\section{Findings}

The capacitance and inductance of a typical ACF connection were estimated from the measured transient response using Kirchhoff's Voltage Law. The method for estimation of $R, L$, and $C$ from the transient response is discussed, as are the $R L C$ effects on the high frequency electrical characteristics of the ACF connection.

\section{Research limitations/implications}

There was decay time deviation between the calculation and the experiment. It may be resulted from the skin effect in the high frequency response and the adhesive surrounding joint as well. The main reason may be the capacitance dielectric lost. Further research work will be done to test the dielectric lost in the ACA joint.

\section{What is original/value of paper}

This paper presents a new method to characterise the high frequency properties of ACA interconnections and will be of use to engineers evaluating the performance of ACF materials in high frequency applications.

Keywords: ACF, Dielectric properties, high frequency, electrical conductivity, capacitance, inductance, resistance. 


\section{INTRODUCTION}

The use of Anisotropic Conductive Adhesives (ACAs) provides a simple method for creation of high density interconnections (Liu, 1999). Industrial applications of ACAs have become increasingly common over the last two decades (Liu, 2001). They offer advantages in terms of low assembly temperature, higher component density, and reduced package size (Dudek et al., 1999). ACAs have been used in fine pitch packaging applications such as flip chip die-attach and LCD display assembly. ACAs are commonly used in the form of pre-formed films, referred to as Anisotropic Conductive Films (ACFs).

Conductive adhesives are of increasing interest for future electronics assembly for high-frequency applications. There have been a number of previous studies of the high frequency performance of ACF bonding. For example Dernevik et al. (1997) and Shilbom et al. (1998) measured the performance of ACF bonded test structures and showed that their transmission performance in the range of $40 \mathrm{MHz}$ to $21 \mathrm{GHz}$ is similar to that of solder, and Yim et al. (1999) showed acceptable performance of ACFs up to $13 \mathrm{GHz}$.

Several high frequency models of ACF joints have also been developed. For example, Ahn et al. (1999) and Yim et al. (1999) proposed equivalent circuit models of the ACF joint, consisting of resistors, $R$, inductors, $L$, and capacitors, $C$. Ryu et al. (2000) used a genetic algorithm to fit such a model to the measured impedances. However, although such experiments and modelling have been undertaken, the models do not always adequately fit the results. Although the series resistance of a connection can be measured, direct measurement of the $R, L$, and $C$ of the equivalent circuit cannot be made. However, in theory the $R$ and $L C$ product of the equivalent circuit can be calculated from the transient response to a square wave voltage input. In this paper, the transient electrical response of a single type of ACF, consisting of resin cored conductor particles coated with nickel and gold layers and carried in an epoxy resin matrix, is investigated and from the measurement results the values of $R, L$, and $C$ for the ACF joint equivalent circuit were estimated. 


\section{EXPERIMENTAL METHOD}

\section{Chip and substrate interconnection patterns}

The area of the experimental chip was $3 \mathrm{~mm} \times 11 \mathrm{~mm}$, with 60 groups of bumped bond pads arranged around the periphery. Each group consists of 5 bumps with a height of $4 \mu \mathrm{m}$ and area of $50 \mu \mathrm{m} \times 70 \mu \mathrm{m}$. Figure 1 shows a group of bumps on the chip. The bump pitch/spacing was $70 \mu m$. Three of the bumps are connected by an $\mathrm{Al}$ film for joint resistance measurement using the four points probe (FPP) method. The other two bumps are designed for insulation resistance measurements and are not connected.

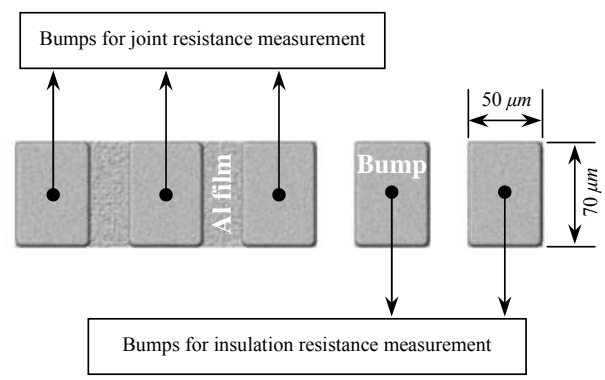

Figure 1. A group of bumps on the chip

Flex substrates $(\mathrm{Au} / \mathrm{Ni} / \mathrm{Cu}$ on Upilex) were used in this experiment. The trace pattern corresponding to the chip bond pad group in Figure 1 is shown in Figure 2.



Figure 2. A group of pads on the substrate

\section{ACF material}

The ACF studied in the experiment employs a random dispersion of conductive particles. It was a commercially available material designed for fine pitch interconnection. The manufacturer's data gave the 
diameter of the ACF particles to be $3.5 \mu \mathrm{m}$ and the particle density to be $3.5 \mathrm{million} / \mathrm{mm}^{3}$. This resulted in a particle density on the pads of about $5 \times 10^{3} / \mathrm{mm}^{2}$.

\section{Bonding Process}

All of the chips and substrates were carefully cleaned using ethanol prior to bonding in order to remove any contaminants. ACF preforms were cut into the correct size for pre-bonding. Two Flip Chip Bonding Machines, a Karl Suss 9493 Mauren and a Toray (FC1200-2k-\#95) were used for pre-bonding and final bonding respectively. The bonding parameters are summarized in Table I and were selected according to the ACF specification. Pre-bonding was used to laminate the ACF onto the substrate, followed by final bonding of the chip onto the substrate at a pressure of $100 \mathrm{Mpa}$ and temperature of $180{ }^{\circ} \mathrm{C}$.

\section{Table I}

Bonding Parameters for the ACF Joints

\begin{tabular}{c|c|c|c}
\hline Bonding Process & $\begin{array}{c}\text { Temperature } \\
\left({ }^{\circ} \mathrm{C}\right)\end{array}$ & Pressure (MPa) & Time (s) \\
\hline Pre-bonding & 80 & 10 & 5 \\
\hline Final bonding & 180 & 100 & 15 \\
\hline
\end{tabular}

\section{Four Point Probe (FPP) resistance measurement}

Figure 3 shows a group of ACF joints. There are five ACF joints in a group designed for electrical measurement using the four wire or FPP method. Traces 1 and 5 are connected to a current source, while traces 3 and 4 are connected to an oscilloscope or multi-meter for voltage measurement.

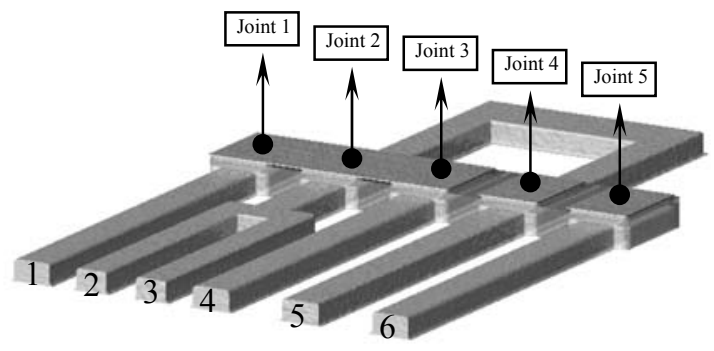


Figure 3. A group of ACF joints

The arrangement for measurement of the electrical response of joint 2 is schematically shown in Figure 4-a. The joint can be represented by the equivalent circuit in Figure 4-b, which is developed from the previous research (Ahn et al., 1999). For DC conditions $R_{1}$ is due to the series resistance of the chip bump and the substrate pad, while $R_{2}$ represents the resistance of the ACF particles trapped in the joint between the bump and the pad. However under AC conditions $R_{2}$ may also include other effects, such as dielectric losses. $C$ and $L$ are the capacitance and inductance of the ACF between the bump and the pad.
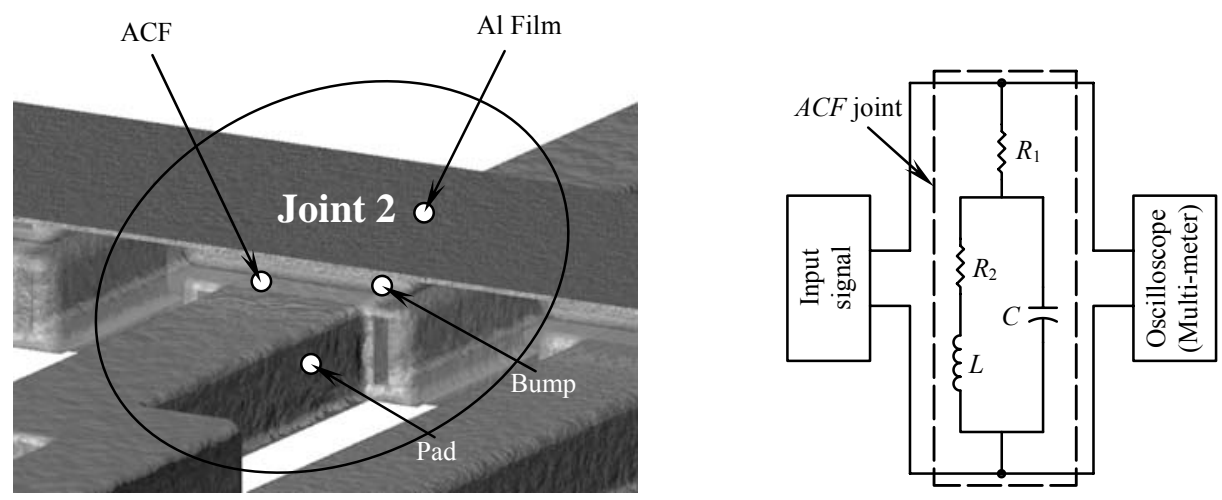

Figure 4. a) Structure of joint 2; b) and its equivalent circuit

\section{Electrical Measurement System}

Figure 5 shows the configuration of the experimental system for DC resistance measurement of the ACF joints. A voltage source is connected to trace 1 and trace 5 , and a volt-meter is connected to trace 3 and trace 4 as shown in Figure 3. $V R$ is a variable resistor used for accurately setting the test current, which is measured by the ammeter, A.

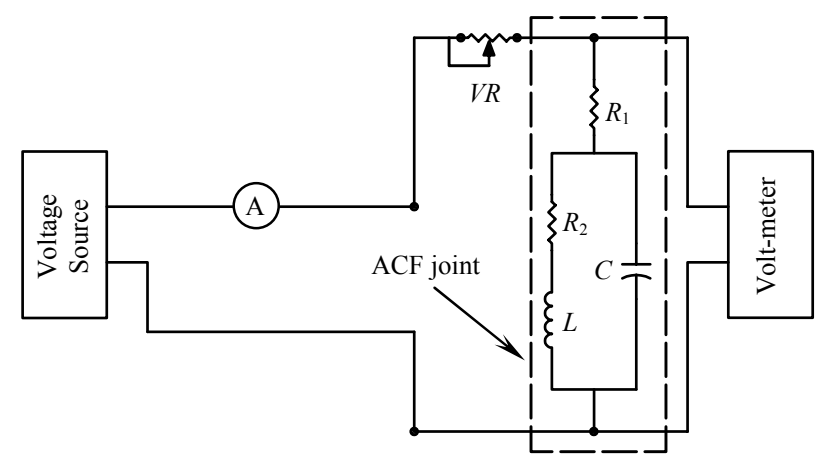


Figure 5. Experimental configuration for the DC joint resistance measurements

The experimental configuration shown in Figure 6 was used to determine the $R L C$ response of the ACF joints to a square wave input signal. A voltage square wave signal was supplied by a function generator via a DS0026 current amplifier, $V R$ is a variable resistor as before. A $1 K$ resistor and a $100 \mathrm{p} F$ capacitor were used to filter the input to the current amplifier. A Tektronix TDS 3014 digital oscilloscope was used for data acquisition. In order to shield out noise, an aluminium shielding box was used to enclose the amplifier circuitry and the test specimen. All of the ground terminals (including the equipment ground) were connected to this box.

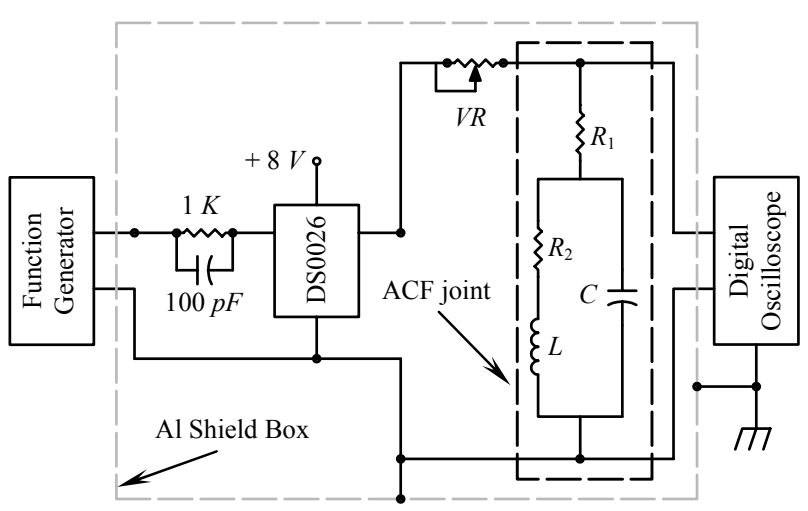

Figure 6. Experimental configuration for the $R L C$ response measurement

A $10 \mathrm{MHz}$ signal was used in this work, due to the capabilities of the oscilloscope available. This frequency is low compared with modern RF and digital circuit applications, but was considered sufficient to establish the validity of the proposed measurement technique. 


\section{THEORY}

For a constant current, the capacitance and inductance in a joint do not affect its impedance, however for a rapidly varying current input, such as in RF or high speed digital circuits, the stray capacitances and inductances present within the joint may result in distortion of the signal. These distortion effects typically include signal attenuation and cross-talk between adjacent conductors but, particularly in digital circuits, the distortion may be apparent as a time delay after any step change in input current before the output signal becomes stable. Where both inductive and capacitive parasitics are significant there may be a transient oscillatory component to this transient response, sometimes known as ringing. This phenomenon is also called the $R L C$ response. The values of $L$ and $C$ predominantly determine the frequency of this ringing, whilst the value of $R$ controls the rate of decay, or damping, of the oscillations.

The series resistance of a joint can be directly measured at low frequency, however at high frequency there may effectively be additional resistive losses due to for example current crowding due to the skin effect and the dissipation of energy in the dielectric of any stray capacitances.

The parasitic capacitance of an ACF joint can be assumed to be primarily due to the layer of adhesive resin forming the bulk of the joint area, which is effectively the dielectric layer in a parallel plate capacitor formed by the two contacts being interconnected and as will be seen later this capacitance can be estimated from the known geometry and materials. The physical original of the inductance of the ACF joint is more complicated as it involves the joint, the contact areas, the bump, the pad and the particles, and is therefore much more difficult to calculate from first principles. However, it can be estimated from the RLC response using the relationship between $L, C$ and the period of the oscillations, $T$.

\section{Equations for the RLC response}

By considering the RLC circuit depicted in Figure 7 with a current input $i(t)$ and voltage output $y(t)$, we may obtain three differential equations by applying Kirchhoff's Voltage Law around the loop indicated by $i(t)$. 


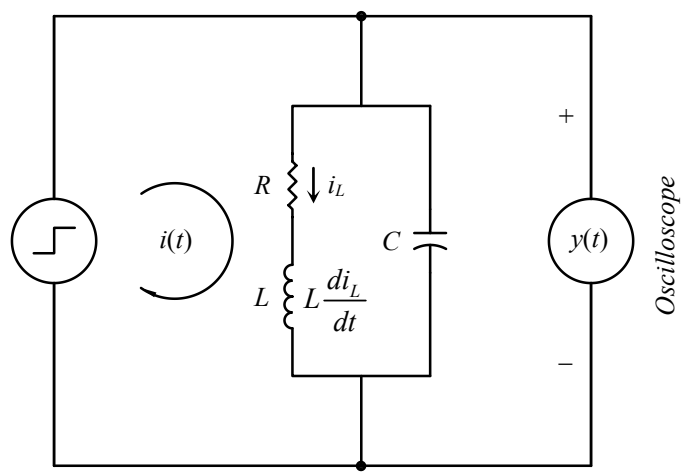

Figure 7. $R L C$ circuit to illustrate the derivation of the input-output relationship

$$
y(t)=v_{c}(t)
$$

$$
C \frac{d v_{c}(t)}{d t}=i(t)-i_{L}(t)
$$

$$
L \frac{d i_{L}(t)}{d t}=v_{c}(t)-R i_{L}(t)
$$

From Equations (1) to (3), a second-order differential equation can be derived to relate $y(t)$ and $i(t)$.

$$
\frac{d^{2} y(t)}{d t^{2}}+\frac{R}{L} \frac{d y(t)}{d t}+\frac{1}{L C} d y(t)=\frac{R}{L C} i(t)
$$

The solution to equation 4 may or may not be oscillatory, depending on the relative magnitudes of R, L and $\mathrm{C}$, but figure 8 shows a classic oscillatory or under-damped $R L C$ voltage response profile for the circuit shown in Figure 7. For such an under-damped situation to occur:

$$
\left(\frac{R}{L}\right)^{2}-\frac{4}{L C}<0
$$

For the step input $i(t)$ in Figure 8, the oscillatory form of the complementary function of the differential Equation (4), is:

$$
y(t)=e^{-\alpha t}\{A \cos \beta \cdot t+B \sin \beta \cdot t\}+R i(t)
$$


The characteristic equation of Equation (4) is:

$$
\lambda^{2}+\frac{R}{L} \lambda+\frac{1}{L C}=0
$$

which has the complex roots:

$$
\lambda_{1}, \lambda_{2}=\alpha \pm \beta \bullet j=\frac{-\frac{R}{L} \pm \sqrt{\frac{4}{L C}-\left(\frac{R}{L}\right)^{2}} \bullet j}{2}
$$

Hence, Equation (6) can be written as:

$$
y(t)=e^{-\frac{R}{2 L} t}\left\{A \cos \left[\frac{1}{2} \sqrt{\frac{4}{L C}-\left(\frac{R}{L}\right)^{2}}\right] t+B \sin \left[\frac{1}{2} \sqrt{\frac{4}{L C}-\left(\frac{R}{L}\right)^{2}}\right] t\right\}+R i(t)
$$

Or:

$$
y(t)=\sqrt{A^{2}+B^{2}} e^{-\frac{R}{2 L} t} \sin \left\{\left[\frac{1}{2} \sqrt{\frac{4}{L C}-\left(\frac{R}{L}\right)^{2}}\right] t+\operatorname{actg}\left(\frac{A}{B}\right)\right\}+R i(t)
$$

From Equation (10), we can obtain the period of the transient response.

$$
T=\frac{2 \pi}{\beta}=\frac{4 \pi}{\sqrt{\frac{4}{L C}-\left(\frac{R}{L}\right)^{2}}}
$$

Equation (11) can be rearranged to allow calculation of the inductance given $T, R$ and $C$ :

$$
L^{2}-\frac{T^{2}}{4 \pi^{2} C} L+\frac{R^{2} T^{2}}{16 \pi^{2}}=0
$$

However, for the experimental values found in this work:

$$
R^{2} T^{2}<<16 \pi^{2}
$$

Thus, Equation (12) can be approximated as:

$$
L^{2}-\frac{T^{2}}{4 \pi^{2} C} L=0
$$

which gives:

$$
L=\frac{T^{2}}{4 \pi^{2} C}
$$

Moreover, the period and the frequency $f$ of the response are given by: 


$$
T=2 \pi \sqrt{L C}, f=\frac{1}{2 \pi \sqrt{L C}}
$$

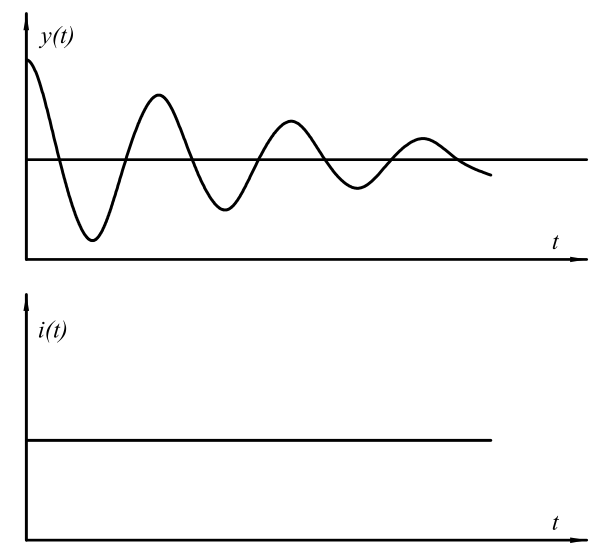

Figure 8. $R L C$ response to a step input

The rate of decay of the oscillations described by equation 9 is characterised by the time constant $2 \mathrm{~L} / \mathrm{R}$ i.e. the oscillations will have fallen to $37 \%\left(e^{-1}\right)$ of their initial magnitude after a time of $2 \mathrm{~L} / \mathrm{R}$.

\section{Estimation of the capacitance of an ACF joint}

In order to estimate the parasitic capacitance of an ACF joint it can be considered as an ideal, parallel plate capacitor, consisting of a slab of insulating material with dielectric constant, $\varepsilon$, between two perfectly conducting plates as shown in Figure 9. In this instance the plates are the substrate and chip bond pads.

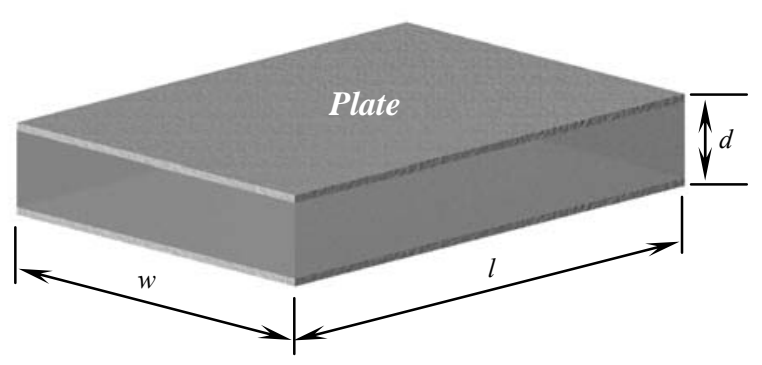

Figure 9. Classical parallel plate capacitor

The capacitance, $C$, of the ACF joint is, therefore:

$$
C=\frac{\varepsilon_{r} \varepsilon_{0} w l}{d}
$$

where 


$$
\begin{aligned}
& \varepsilon_{r}=\text { dielectric constant of the slab material } \\
& d=\text { distance between the plates, } m \\
& w=\text { width of the slab, } m \\
& l=\text { length of the slab, } m
\end{aligned}
$$

For the experiment parameters used in the bonding process the transformation (degree of compression) of the ACF particles is to about $60 \%$ of their original diameter of $3.5 \mu \mathrm{m}$, and thus the distance, $d$, between the plates is about $2 \mu m$ (Dou, 2003). For the ACF joint used in the experiment, the other values are $w=50$ $\mu m, l=70 \mu m$ and $\varepsilon_{r}=4.5$, whilst $\varepsilon_{r} \varepsilon_{0}=4.5 \times 8.85 \times 10^{-12} \mathrm{~F} / \mathrm{m}$. Hence using equation (17) the capacitance of the joint is calculated to be:

$$
C=6.97 \times 10^{-2} \quad p F
$$

\section{Estimation of the substrate and chip pad resistance}

Although the FPP resistance measurement method prevents interconnection resistances affecting the measured resistance, the substrate and chip pads are in series with the ACF connection and their resistance therefore needs to be considered. The total DC resistance of an ACF joint therefore consists of 5 parts, as shown in Figure 10 (Dou et al., 2003). These are the resistances of the chip bump and PCB pad, $R_{\text {bump }}$ and

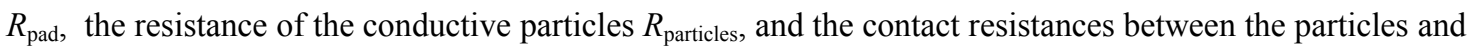
bump or pad $R_{\text {contact. }} R_{\text {contact }}+R_{\text {particles }}+R_{\text {contact }}$ will clearly consist of the parallel resistances through all of the conductor particles present within the individual connection area. The conduction mechanisms for the contact resistance are complicated and are still poorly understood, because they result from a mechanical rather than metallurgical contact (Oguibe et al., 1998). Many factors can affect the contact resistance, such as the nature of the contact surface, thermal stress, deformation degree, etc.

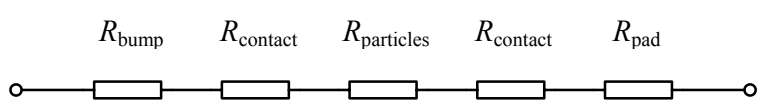

Figure 10. DC equivalent circuit of the ACF joint 
The structure of the chip bump and substrate bond pad metallization used in the experiment is shown in Figure 11. Each chip bump consisted of three layers, an $A l$ film, a $N i$ layer and an $A u$ layer. The $A l$ film and $N i$ layer are slabs, but the $A u$ layer is very thin. In order to simplify estimation of the resistance of the $A u$ layer, it is also assumed as a slab. The pad metallization also had three parts, a $C u$ layer, a $N i$ layer and an $A u$ layer as shown in Figure 9-b. Both the $N i$ layer and the $A u$ layer are thin, and are also assumed to be slabs for the estimation of the pad resistance.

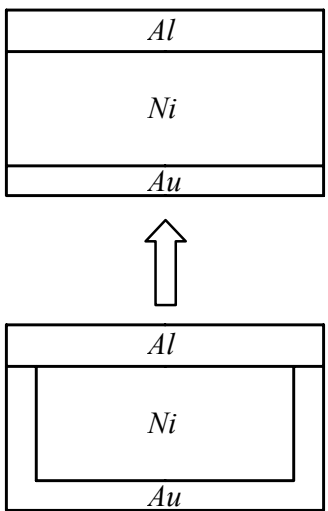

a)

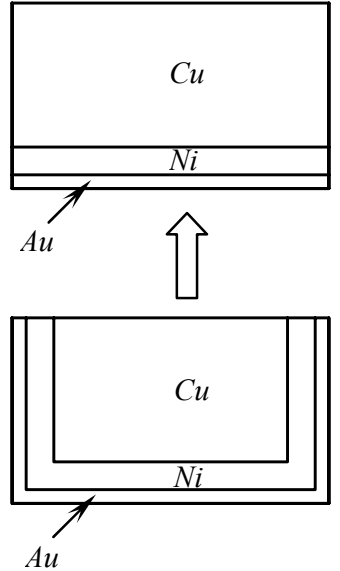

b)

Figure 11. Construction of the connections and their approximation a) chip bumps; b) substrate pads

The resistance, $R$, of each layer can be calculated using:

$$
R=\frac{d}{\sigma w l} \Omega
$$

The dimensions and calculated resistances of each of the bump and the pad layers are shown in Table II. Why do the areas vary through the stack of slabs???? The individual slab resistances are in series, so the total resistance of the bump is:

$$
R_{\text {bump }}=7.58 \times 10^{-3}+7.24 \times 10^{-2}+3.16 \times 10^{-3}=8.31 \times 10^{-2} \mathrm{~m} \Omega
$$

and that of the pad is:

$$
R_{\text {pad }}=7.38 \times 10^{-2}+1.02 \times 10^{-1}+3.16 \times 10^{-3}=1.79 \times 10^{-1} \mathrm{~m} \Omega
$$




\begin{tabular}{|c|c|c|c|c|c|c|}
\hline \multicolumn{7}{|c|}{$\begin{array}{l}\text { Table II } \\
\text { Bump and pad resistances for the ACF joint }\end{array}$} \\
\hline \multicolumn{7}{|c|}{ Slab geometry } \\
\hline & Material & $\begin{array}{l}\text { Length } \\
(l \mu m)\end{array}$ & $\begin{array}{l}\text { Width } \\
(w \mu m)\end{array}$ & $\begin{array}{l}\text { Height } \\
(d \mu m)\end{array}$ & $\begin{array}{l}\text { Conductivity } \\
(\sigma / \mu m \cdot \Omega)\end{array}$ & $\begin{array}{c}\text { Resistance } \\
(m \Omega)\end{array}$ \\
\hline \multirow{3}{*}{ 言 } & $A l$ & 70 & 50 & 1 & 37.7 & $7.58 \mathrm{E}-3$ \\
\hline & $\mathrm{Ni}$ & 69 & 49 & 3.5 & 14.3 & $7.24 \mathrm{E}-2$ \\
\hline & $A u$ & 70 & 50 & 0.5 & 45.2 & $3.16 \mathrm{E}-3$ \\
\hline \multirow{3}{*}{ 芯 } & $\mathrm{Cu}$ & 70 & 39 & 12 & 59.6 & $7.38 \mathrm{E}-2$ \\
\hline & $N i$ & 70 & 49 & 5 & 14.3 & $1.02 \mathrm{E}-1$ \\
\hline & $A u$ & 70 & 50 & 0.5 & 45.2 & $3.16 \mathrm{E}-3$ \\
\hline
\end{tabular}

$R_{1}$ in fig4(b) is the combined resistance of the bump and the pad in the ACF joint, therefore $R_{1}$ is

$$
R_{1}=R_{\text {bump }}+R_{\text {pad }}
$$

Substituting the previously calculated values into Equation (17), the estimated value of $R_{1}$ is:

$$
R_{1}=R_{\text {bump }}+R_{\text {pad }}=0.262 \mathrm{~m} \Omega
$$




\section{EXPERIMENTAL RESULTS}

Firstly, the DC resistance of a single ACF joint was measured and for a $1 \mathrm{~mA}$ test current the voltage drop was found to be $0.040 \mathrm{mV}$ equating to a resistance of $40 \mathrm{~m} \Omega$. This is much larger than the previously calculated value for $R_{1}$, i.e.:

$$
R_{1}<<R_{\text {joint }}
$$

Therefore, $R_{1}$ contributes little to the joint resistance, and can be ignored during further consideration of the $R L C$ response. As defined in Figure 4-b, resistance $R_{2}$ results from conduction through the contact areas and the metal layers of the particles. The resistance of the one ACF joint has been estimated to vary from $2 m \Omega$ to $6 m \Omega$ if the particles deformation degree is more than $30 \%$ (Dou et al., 2003). This shows that the DC resistance of the joint is dominated by the contact resistances between the particles and the bump/pad.

Secondly, the $R L C$ response of the ACF joint was captured. The Figures 12-a and 12-b show the input signal and $R L C$ response respectively. The input current was $0 m \mathrm{~A}-7 m \mathrm{~A}$ peak to peak for $V R$ set to $1 \mathrm{k} \Omega$ and the frequency of the test signal was $10 \mathrm{MHz}$.

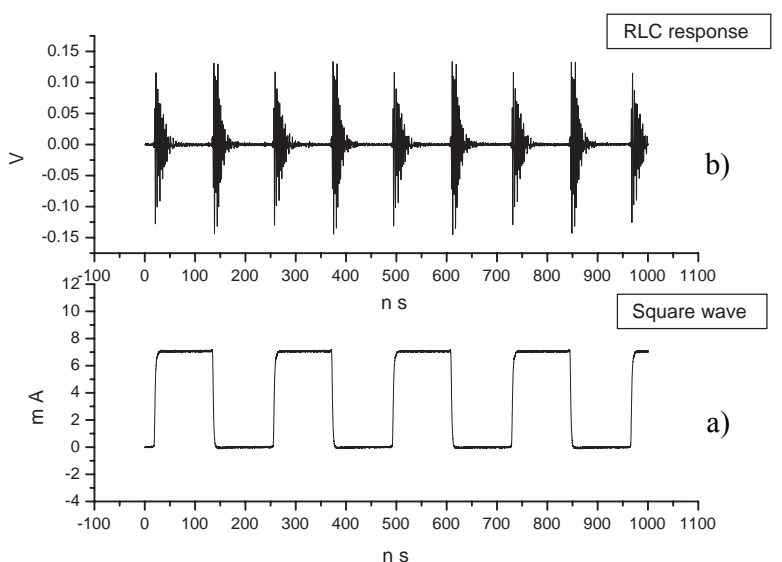

Figure 12. a) $R L C$ response b) input signal

Figure 12 shows the measured voltage response on an expanded time axis. The response plotted is the mean of 16 acquisitions by the digital oscilloscope. If we consider $i(t)$ to be a step input for simplicity, Figure 12 can be considered as a classic $R L C$ response as shown in Figure 8. 


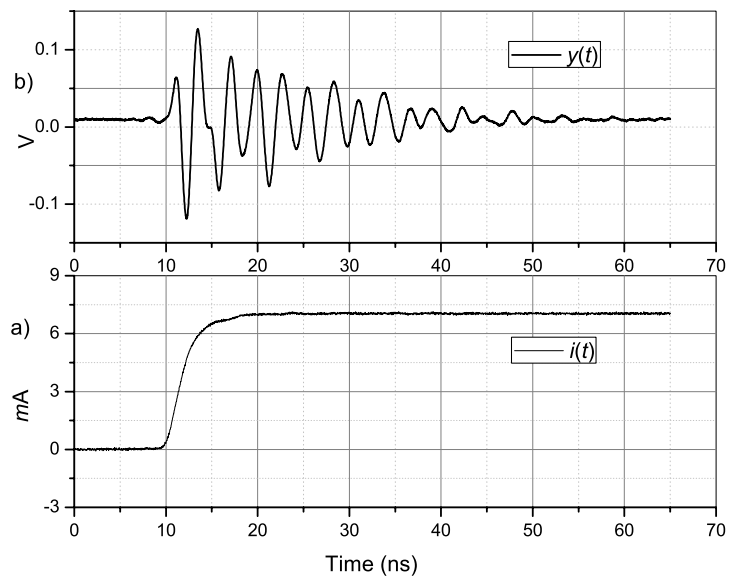

Figure 12. Averaged voltage response and input current

The frequency of oscillation can be measured from the time between the signal crossing the steady state voltage, which is slightly above zero due to the DC resistance of the joint. The accuracy of this measurement is improved by averaging over several cycles and in Figure 13 it can be seen that there are 5 whole cycles between the zero crossings at $16.4 \mathrm{~ns}$ and $30.4 \mathrm{~ns}$. From this, the period of the RLC transient response is:

$$
T=\frac{30.4-16.4}{5} n s=2.8 n s
$$

and the and the frequency is therefore:

$$
f=\frac{1}{T}=357 \quad M H z
$$

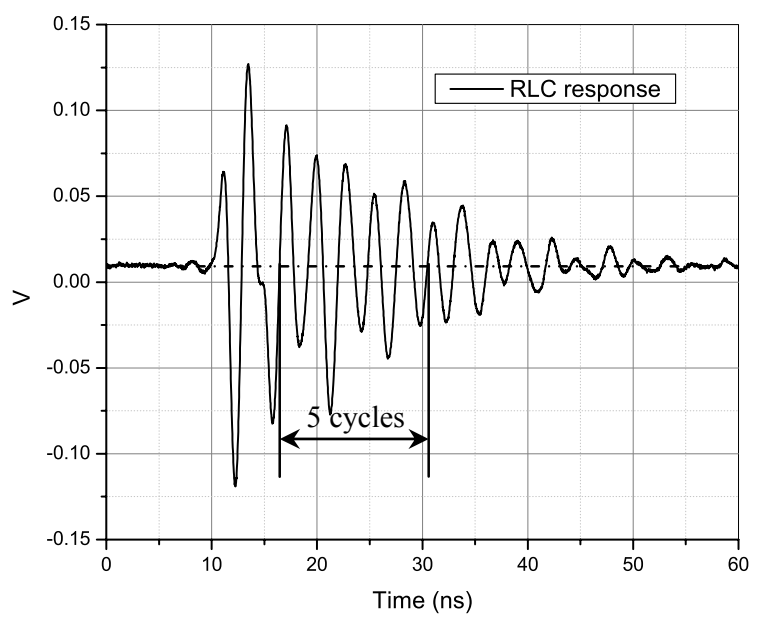

Figure 13. RLC response for period counting 
Substituting the measured value for $T$ and the previously calculated value of $C$ into Equation (15), we obtain $L$

$$
L=\frac{T^{2}}{4 \pi^{2} C}=\frac{\left(2.8 \times 10^{-9}\right)^{2}}{4 \pi^{2} \times 6.97 \times 10^{-14}}=2.85 u H
$$

The RLC decay time $\tau$ is around $30 \mathrm{~ns}$ as shown in Figure 13, however the derived one from equation (10) is $2 \mathrm{~L} / \mathrm{R}_{2}$, i.e. $0.14 \mathrm{~ms}$, which is about 5000 times bigger than the calculation. This may be resulted from the skin effect on the complex ACA joint in the high frequency response. The actual capacitance of the joint should be bigger than the calculation due to the adhesive surrounding environment, that may be another reason to contribute to the big decay time. The main reason may be the capacitance dielectric lost. The series resistance as shown in Figure 7 can be calculated as:

$$
R=\frac{2 L}{\tau}=\frac{2 \times 2.85 \times 10^{-6}}{30 \times 10^{-9}}=190 \Omega
$$

Thus, the equivalent parallel resistance $R_{P}$ can be written as:

$$
R_{p}=\frac{R^{2}+(2 \pi f L)^{2}}{R}=\frac{190^{2}+\left(2 \pi \times 357 \times 10^{6} \times 2.85 \times 10^{-6}\right)^{2}}{190} \approx 215068 \Omega
$$

Then, the dielectric dissipation factor, $\operatorname{Tan} \delta$, is:

$$
\operatorname{Tan} \delta=\frac{\frac{1}{2 \pi f C}}{R_{p}}=\frac{\frac{1}{2 \pi \times 357 \times 10^{6} \times 0.0697 \times 10^{-12}}}{215068} \approx 2.98 \%
$$

Therefor e, the decay time deviation may be resulted from the capacitance dielectric lost.

In conclusion, a detailed equivalent circuit RLC model of an ACF joint has been proposed, where $R_{1}$ is about $0.3 m \Omega, R_{2}$ is $40 m \Omega, \mathrm{C}$ is $0.0697 p \mathrm{~F}$, and $L$ is $2.85 \mu \mathrm{H}$. The resistances within the model do not affect the period of the high frequency response period. The resonant frequency of the joint should be close to the response frequency. 


\section{Summary}

In this study, a high frequency equivalent circuit model for ACF joints was assumed. The model was used to predict the transient response of an ACF joint to a square wave current input.

The capacitance and inductance of the ACF joint can be calculated from the RLC response when a square wave input signal is applied using the high frequency model assumed in this paper. The period of the transient response equation relating to the capacitance and inductance is $T=2 \pi \sqrt{L C}$.

The calculated value of the ACF joint resistances due to the bump and the pad are much lower than the measure contact resistances. The model predicts that the resistances of the ACF joint have little effect on the response of the ACF joint at high frequency.

The resonant frequency of the ACF joint should be close to the response frequency, when the joint is used at high frequency close to the resonant frequency, the inductance and the capacitance of the ACF joint will have a significant effect on the electrical characteristic of the joint i.e., it will have a high impedance.

The decay time from calculation is much smaller than the plot. The skin effect and the adhesive surrounding joint are thought to be responsible for the deviation. The main reason may be the capacitance dielectric lost. Further research work will be done to test the dielectric lost in the ACA joint. 


\section{Acknowledgements}

The authors acknowledge the financial support provided by the Research Grant Council of Hong Kong for the Co-operative Research Center on Conductive Adhesive Technology for High Density Electronic Packaging (Project No. 8720003). 


\section{References}

Ahn S., Ryu W., Yim M.-J., Lee J., Jeon Y.-D, W., Kim W. Paik K.-W. and Kim J. (1999), “Over $10 \mathrm{GHz}$ Equivalent Circuit Model of ACF Flip-chip Interconnect using Ni-filled Ball and Au-coated Polymer Balls", Proceedings of the $24^{\text {th }}$ IEEE/CPMT International on Electronics Manufacturing Technology Symposium, Austin, TX, USA, pp.421-425

Dernevik M., Shilbom R., Lai Z., Starski, P. and Liu J. (1997), "High-frequency measurement and modelling of anisotropic electrically conductive adhesive flip-chip joint", EEP-Vol. 19-1 Advances in Electronic Packaging, Proceedings of the ASME INTERpack conference, Kohala Coast, Hawaii, pp.177184

Dou G. B., Chan Y. C., Liu J. (2003), "Electrical Conduction Characteristics of Anisotropic conductive Adhesive Particles", Journal of Electronic Packaging, Transactions of the ASME, Vol. 125, pp.609-616

Dudek R., Meinel S., Schubert, A., Michel, B., Dorfmüller, L., Knoll, P. M. and Baumbach J. (1999), "Flow Characterization and Thermo-Mechanical Response of Anisotropic Conductive Films", IEEE Transactions On Components and Packaging Technology, Vol. 22, No. 2, pp.177-185

Liu J. (1999), “Conductive Adhesive for Electronics Packaging”, Electrochemical Publications Ltd., Port Erin, Isle of Man, British Isles

Liu J. (2001), “ACA Bonding Technology for Low Cost Electronics Packaging Applications Current Status and Remaining Challenges", Soldering \& Surface Mount Technology, Vol. 13, No. 3, pp.3957

Oguibe, C. N., Mannan, S. H., Whalley D. C. \& Williams D. J. (1998) “Conduction Mechanisms in Anisotropic Conducting Adhesive Assembly", IEEE Transactions on Components, Packaging and Manufacturing Technology - Part A. Vol. 21, No. 2, pp.235-242

Ryu W., Jin M., Ahm S., Lee J., Kim W., Paik K. W., and Kim J. (2000), “High-Frequency SPICE Model of Anisotropic Conductive Film Flip-Chip Interconnections Based on a Genetic Algorithm", IEEE Transactions On Components and Packaging Technology, September 2000, Vol. 23, No. 3, pp.542-545 
Shilbom R., Dernevik M., Lai Z., Starski P. and Liu J. (1998), “Conductive Adhesive for HighFrequency Applications", IEEE Transactions on Components, Packaging, and Manufacturing Technology, Part A, Vol. 21, No. 3, pp.469-477

Yim M.-J., Ryu W., Jeon Y.-D., Lee J., Ahn S. and Paik K.-W. (1999), "Microwave model of anisotropic conductive film flip-chip interconnections for high frequency applications", IEEE Transactions on Components, Packaging, and Manufacturing Technology, Vol. 22, December 1999, pp.575-581 